\title{
Intracranial extension of a non-striated embryonal rhabdomyosarcoma of the orbit
}

\author{
D. SEVEL
}

Department of Ophthalmology, University of Cape Town, Groote Schuur Hospital, South Africa

The subject of embryonal sarcomata of the orbit has already been adequately reviewed by $\tilde{H}_{\omega}^{\mathrm{E}}$ Calhoun and Reese (1942), Frayer and Enterline (1959), Porterfield and Zimmerman $\stackrel{\circ}{\circ}$ (1962), Howard and Casten (1963), Reese (1963), Wybar (1964), and Ashton and Morgan (1965). A further case is presented to emphasize the necessity and value of detailed neurological examination (including carotid angiography and brain-scan) even in the $\vec{z}$ absence of symptoms and signs of intracranial extension. This is the first time that a brain-scan has been used to demonstrate the spread of an embryonal sarcoma.

\section{Case report}

A coloured boy aged 6 years was first seen on May 19, 1967, when he gave a history of having fallen 3 weeks previously and of "injuring his left eye". He was feverish and generally unwell buto there was no neurological deficiency and no evidence of cerebral involvement or other symptoms. $X$ ray of chest was normal.

Examination The left eye was proptosed $(24 \mathrm{~mm}$.) centrally, the lids were swollen and oedematous,, and the conjunctiva was markedly chemotic and congested (Fig. I). Total internal and external ophthalmoplegia, together with complete ptosis, was noted on this side. The fundus showed venous congestion and retinal oedema. The visual acuity was counting fingers at $\mathrm{I}$ metre. The right eye $\frac{O}{0}$. and its adnexa were normal.

A fluctuant soft tissue swelling filled the left temporal fossa. The left cheek was swollen and a purulent bloody discharge was noted in the left nostril. Detailed $X$ rays of the skull showed a largeo soft tissue mass which eroded the medial wall of the left orbit, filled the nasal cavity, deviating the septum to the right and filling the maxillary sinus (Fig. 2). Basal views of the skull showed erosion? of the left petrous temporal bone. The inferior and superior orbital fissures were enlarged and the left side of the middle cranial fossa was markedly expanded.

Exploration On May 26, 1967, under general anaesthesia, an oto-laryngologist found that the left nostril was filled with friable tumour material which also occupied the left aural aperture, and involved the entire soft palate and the posterior aspect of the hard palate. Biopsies were taken from both the $e^{\omega}$ tumour in the left choanal aperture and from the soft tissue mass in the left temporal fossa. Histo logical examination showed the features of an undifferentiated embryonal sarcoma consisting of primitive mesenchymal cells. Pleomorphism was a prominent feature and mitoses were common $\$$ While occasional rhabdomyoblasts were identified, cross-striations were not noted in the abundanto cytoplasm of these strap-like cells (Figs 3 and 4 ).

The enlargement of the superior orbital fissure indicated possible intracranial extension of the orbital tumour. On June 6, 1967, left carotid angiography revealed marked upward displacemen $\mathbb{B}$ of the left middle cerebral artery. The anterior cerebral artery filled only with gross compressiong 


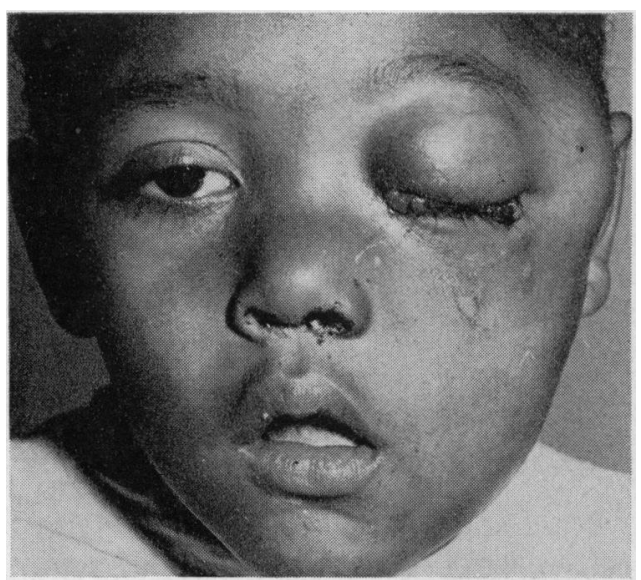

FIG. I Left eye proptosed and the temporal fossa filled by a soft tissue mass. The left cheek is swollen and a discharge is noted from the left nostril

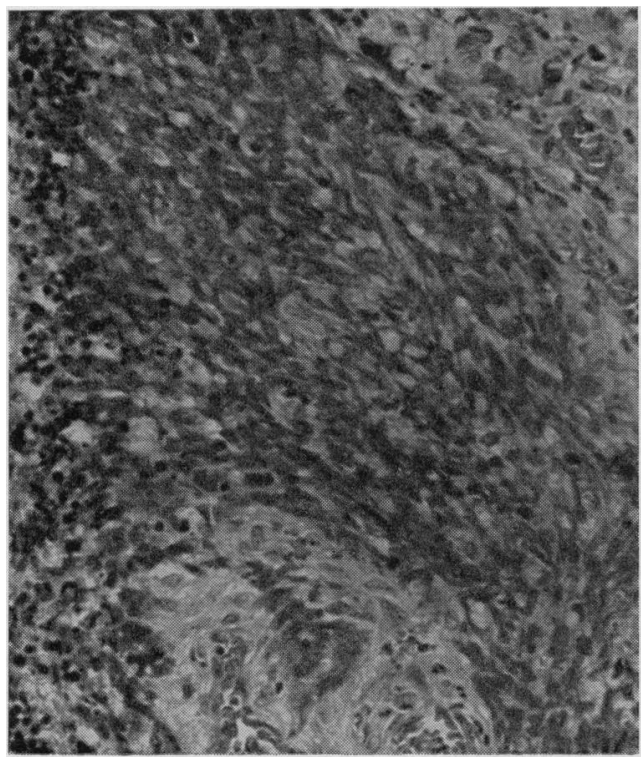

FIG. 3 Biopsy showing ovoid, round, and spindle cells with abundant eosinophilic cytoplasm. Haematoxylin and eosin. $\quad \times 18$

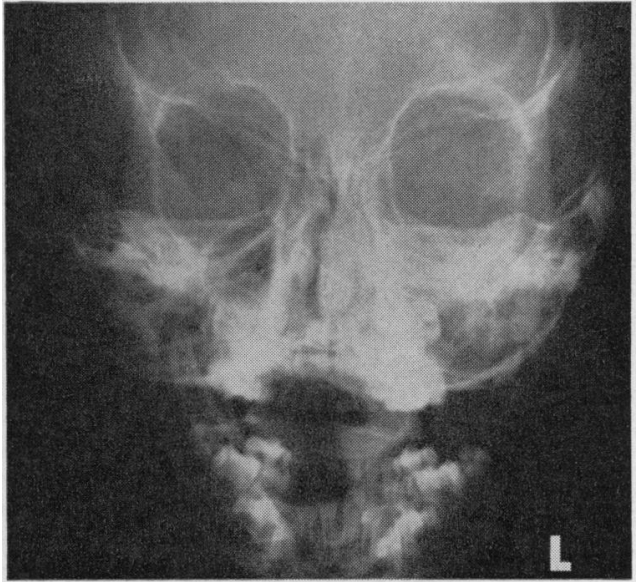

FI G. 2 Skull $\mathrm{x}$-ray (postero-anterior view), showing a soft tissue mass filling the left maxillary antrum, extending into the nasal cavity, and deviating the nasal septum to the right

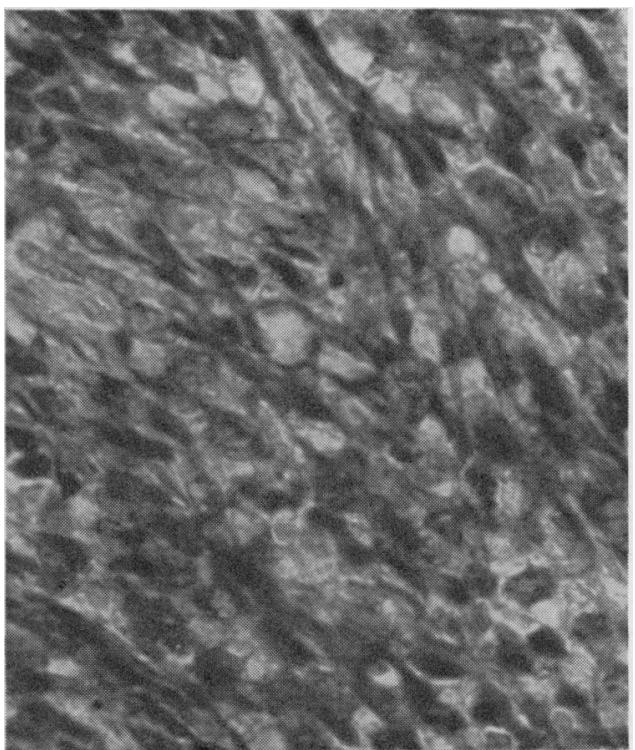

F I G. 4 High-power view of Fig. 3, showing straplike cells. Cross-striations are not present. Haematoxylin and eosin. $\quad \times 48$

There was upward and backward displacement of the carotid syphon and a tumour blush was noted in the left temporal region of the brain (Fig. 5, overleaf).

Brain-scan On June 10,1967 , the intracranial extension of the embryonal sarcoma was confirmed with the aid of brain-scan using Technetium 99 (Fig. $6 a$ and $b$, overleaf).

Three days before the procedure the patient was given to minims of Lugol's iodine three times a day to reduce the thyroid uptake activity of the Technetium 99. On the day of the test, I mc. 
Technetium 99 was injected intravenously one hour before the scan. to chart the brain fields.

A positron scanner was used

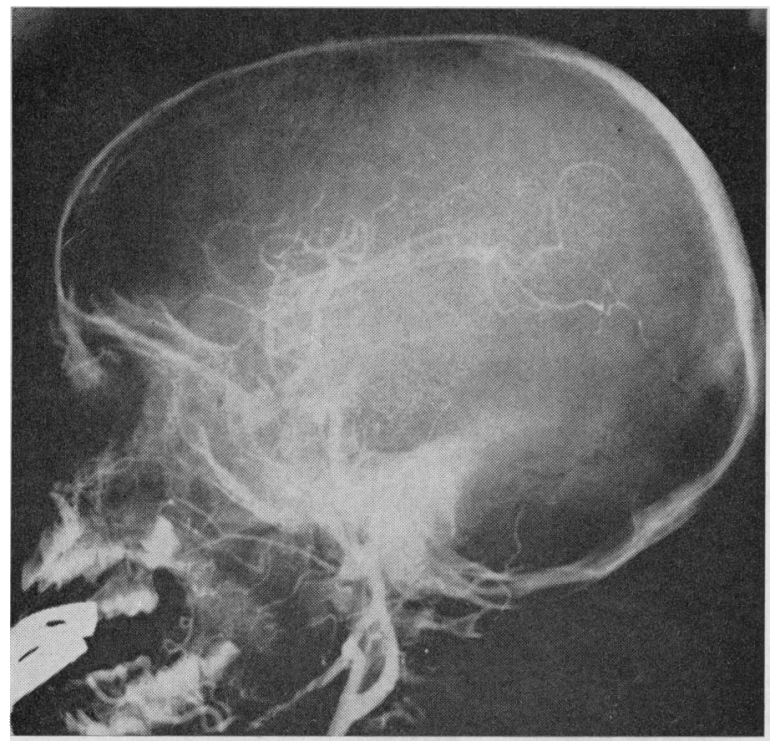

FIG. 5 Left carotid angiogram (lateral view), showing upward displacement of the middle cerebral artery and upward and backward displacement of the carotid siphon. There is a tumour blush in the left temporal region

Outcome The patient's general condition deteriorated, he refused to eat, and became weak. As there was extensive spread of the embryonal sarcoma it was decided that a mutilating surgical operation was not indicated as a primary procedure. Deep $x$-ray and cytotoxic therapy was contemplated, to be followed, if possible, by an exenteration, but the child's parents took him home and refused further hospital treatment. The general practitioner who originally referred the case to hospital confirmed that he died on July 5,1967 . A post mortem examination was not performed.

\section{Discussion}

Rhabdomyosarcomata are classified according to the degree of differentiation attained by the tumour:

(a) Embryonal sarcoma, completely undifferentiated;

(b) Non-striated embryonal rhabdomyosarcomata; rhabdomyoblasts may be recognized but no cross-striations are found;

(c) Striated embryonal rhabdomyosarcomata; cross-striations are noted.

The histological features of this case were those of category $b$ as true striated rhabdomyo- of blasts were not noted. The clinical features (rapid development, galloping spread, and $N$ retrogression with death only 3 months after the onset) are in keeping with the embryonal nature of the tumour.

At no stage during the clinical examination was there any indication of the extensive intracranial spread of the embryonal sarcoma. The spread of orbital embryonal sarcomata into the cranial cavity has already been recognized (Krayenbühl, 1962; Wybar, I964; Ashton and Morgan, I965), but the diagnosis has always been made at operation or post mortem. The advantage of carotid angiography with orbital tumours has been indicated by Krayenbühl ( 1962 ) but the value of the brain-scan to assess the spread of such tumours has not been adequately considered. The brain-scan is a simple procedure 


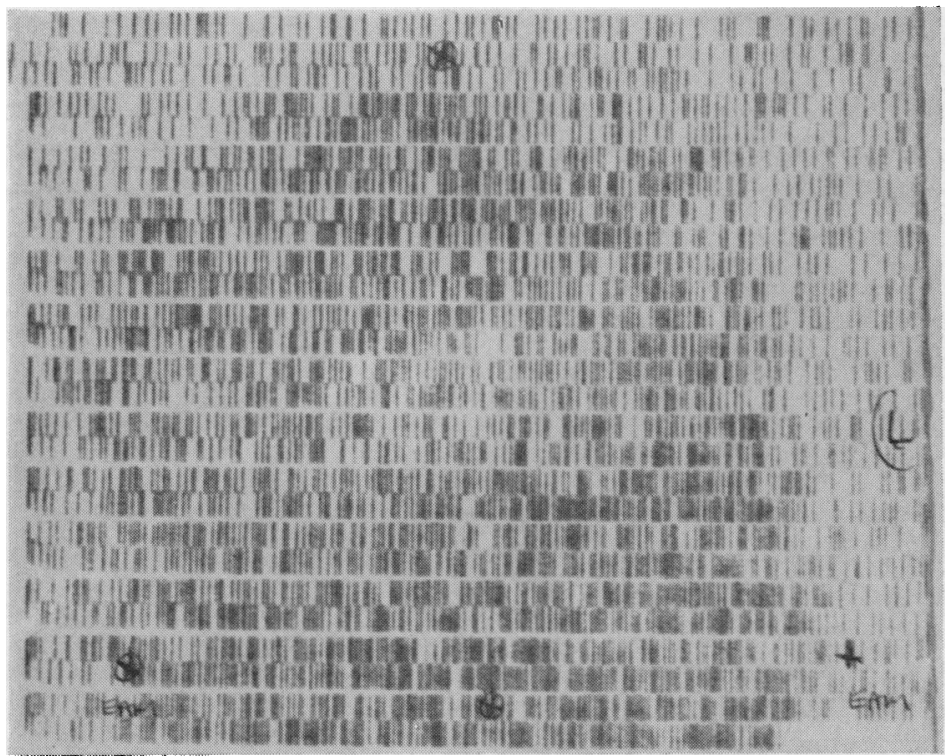

FIG. $6 a$ Brain-scan (Technetium 99), antero-posterior view, showing abnormal area of intracranial activity in temporal region (E.A.M.-External auditory meatus, O.P.—occipital protuberance)

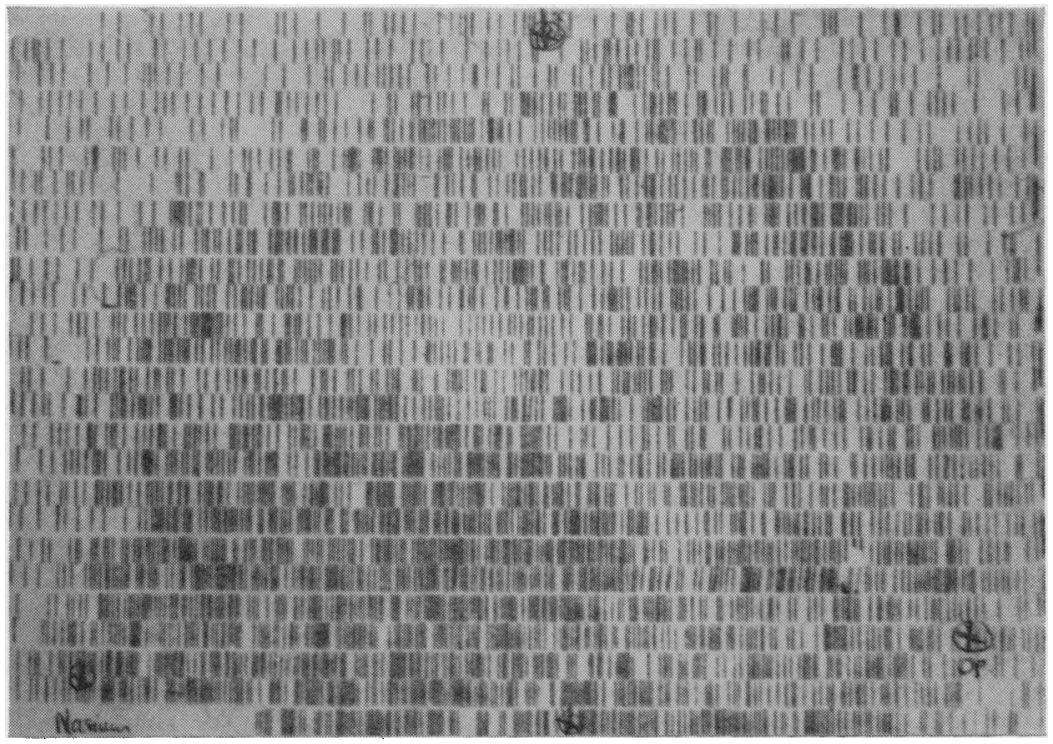

FIG. $6 b$ Brain-scan (Technetium 99), lateral view, showing abnormal area of intracranial activity in left temporal region (E.A.M.-External auditory meatus, O.P.occipital protuberance)

not requiring a general anaesthetic and causing minimal discomfort to the patient. Angiography does not alter the uptake of the radioisotope (Brinkman, 1966). Moore (1948) first proposed the use of radioisotopes for the diagnosis and localization of intracranial lesions. The radioisotopes which have been considered and evaluated are arsenic ${ }^{74}$ 
(Botterell, Lougheed, Morley, Tasker, and Paul, I96I), bismuth ${ }^{206}$, copper ${ }^{64}$ (Bagnall, Benda, Brownell, and Sweet, I958), gallium ${ }^{68}$, mercury ${ }^{197}$, mercury $^{203}$, iodine ${ }^{124}$, iodine ${ }^{131}$, 으 and technetium ${ }^{99}$. The advantage of the last is its rather short half-life. Localization of the isotope depends on the alteration of the blood-brain barrier in the area of disease or in $\stackrel{5}{?}$ the tissue immediately adjacent thereto (Sweet, Ojemann, Aronow, and Brownell, ig66). This permits a greater concentration of isotope than in the surrounding normal brain $\frac{\bar{\sigma}}{\bar{m}}$ and overlying skull and scalp. In the patient under consideration, the radioactive isotope brain-scan was invaluable, as it determined the extent of the intracranial spread of theg tumour and hence the proposed subsequent treatment.

\section{Summary}

A case of a non-striated embryonal rhabdomyosarcoma of the orbit is described where there was no clinical evidence of gross intracranial extension. The value of carotid angio- $\omega$ graphy and brain-scan in such cases is emphasized.

I wish to thank Dr. R. P. van Heerden of Bredasdorp, Cape Province, for referring the patient to the Eye Department at Groote Schuur Hospital and for the follow-up, Dr. J. Marais for the E.N.T. opinion, and $\rightarrow$ Dr. P. le Roux for the neurosurgical investigations.

This investigation was financed by the Gratitude Fund of Ophthalmology, University of Cape Town.

\section{References}

ashton, N., and morgan, g. (1965) 7 f. clin. Path., 18, 699

BAGNALl, H. J., BENDA, P., BROWNELl, G. L., and sWeEt, W. H. (1958) F. Neurosurg., 15, 4 I I BotTerell, E. H., LOUGHeEd, W. M., MORLey, T. P., TASKer, R. R., and PAUl, W. (196I) Canad. med. Ass. 7., 85, 1321

BRINKmaN, c. A. (1966) In "Neurological Diagnostic Techniques", I $3^{\text {th }}$ Annual Houston Neuro-

logical Scientific Symposium, 1965, ed. W. S. Fields, p. 215 . Thomas, Springfield, Ill.

CAlHoun, F. P., and REESE, A. B. (1942) Arch. Ophthal. (Chicago), 27, $55^{8}$

Frayer, w. c., and ENTERLine, H. T. (1959) A.M.A. Arch. Ophthal., 62, 203

hOWARD, G. m., and CASTEN, v. G. (1963) Arch. Ophthal. (Chicago), 70, 319

KRAYENBÜHL, H. (1962) F. Neurosurg., 19, 289

MOORE, G. E. (1948) Science, 107, 569

porterfield, J. F., and zimmerman, L. E. (1962) Virchows Arch. Path. Anat., 335, 329

REESE, A. B. (1963) "Tumors of the Eye", 2nd ed., p. 44I. Hoeber, New York

SWEET, W. H., OJEMANN, R. G., ARONOW, s., and BRownell, G. L. (1966) In "Neurological Diagnostic

Techniques", ed. W. S. Fields, p. I9o. Thomas, Springfield, Ill.

wYbar, к. (1964) Proc. roy. Soc. Med., 57, 738 